\title{
Psychiatry and Darwinism
}

\section{Time to reconsider?}

RIADH T. ABED

A new discipline of evolutionary psychology and psychiatry has been created over the past 20 years (Barkow et al, 1992; McGuire \& Troisi, 1998). Evolutionary science has the potential for subverting many assumptions of the current nonevolutionary disciplines and of opening new avenues of research and theoretical innovations. However, mainstream psychiatry has remained largely oblivious of these developments. Evolutionary concepts are only vaguely understood by many psychiatrists and the subject does not, at present, feature on the curriculum of any official psychiatric training programme. The reasons for this neglect are no doubt complex and varied.

\section{ULTIMATE AND PROXIMATE CAUSATION}

Evolutionary theory makes a distinction between proximate and ultimate causation for a given biological phenomenon. Ultimate causes involve an understanding of the contribution of a trait or system to the reproductive fitness of an organism in its natural (ancestral) environment, while proximate causes are the sum of all the biological processes (biochemical, physiological etc.) that directly produce a given phenomenon. Hence, ultimate causation answers the question why a trait or system exists, whereas proximate causes explain how it works. The concept of ultimate causation is a perspective unique to Darwinian theory and is a potential source of hypotheses and predictions about the possible function of biological systems. Thus, according to this view some psychiatric disorders may have proximate causes only, such as the sequelae of injuries to the brain (e.g. temporal lobe epilepsy) or the damaging effect of individual gene mutations (e.g. Huntington's disease). However, many 'functional' psychiatric disorders may represent accentuations (or dysregulation) of normal human traits (such as anxiety or depression) or be misplaced psychological or behavioural strategies (Marks \& Nesse, 1994). In such cases the identification of ultimate causation becomes crucial for the proper understanding of the nature of the disorder.

Statements regarding ultimate causation (why a given adaptation has evolved) are of a historical nature and, therefore, not directly testable. For example, there would be no direct test to assess the merits of the hypothesis that depression has arisen as a subsystem of agonistic behaviour as opposed to the view that it evolved in relation to attachment behaviour. Nevertheless, to hold the former view will lead to a search for the mechanisms of depression in the basal ganglia (which is likely to have constituted the forebrain when agonistic behaviour evolved), whereas if one holds the latter view the limbic system should be the main target for investigation.

\section{CONCEPTUAL PLUR ALISM: STRENGTH OR WEAKNESS?}

Psychiatry, unlike most other medical sciences, has been characterised by conceptual pluralism (McGuire \& Troisi, 1998). This has meant that a number of competing (and occasionally incompatible) paradigms have coexisted within the field. Is psychiatry's continuing conceptual pluralism a weakness or a sign of healthy diversity? McGuire \& Troisi (1998) have argued convincingly that it has been a sign of weakness rather than strength. The striking weakness of psychiatry is evident from the absence of the most rudimentary rules about the functioning of the human mind. In such an environment any theory, however irrational, can demand equal attention.

Hence, one will not catch a physicist violating Newtonian laws of gravity while generating a hypothesis about a particular phenomenon, yet we regularly find psychiatrists, psychologists and social scientists violating basic biological rules by (for example) assuming the human mind is a blank slate. This is despite the overwhelming body of research evidence to the contrary, as well as the extreme implausibility that an endlessly malleable human brain would have evolved through a process of selection (Barkow et al, 1992; Plotkin, 1997).

One major problem is that there is currently no mechanism for psychiatry to shed or screen out unscientific and erroneous claims that cannot be directly tested empirically. Therefore, diverse and self-contained theories, such as Freudianism, still coexist with such theoretical formulations as behaviourism, despite the fact that both have been demonstrated to have serious flaws and behaviourism in its purest form has been entirely discredited. As a result the various competing paradigms within psychiatry, such as psychodynamics, the neurosciences and cognitive science, are continuing to develop in relative isolation from each other, so that cross-fertilisation is very unlikely or entirely impossible.

In recent years psychiatry has attempted to circumvent such problems by engaging in an atheoretical research enterprise involving gathering masses of data and calculating sophisticated statistical associations. However, such an endeavour of itself cannot generate a scientific discipline, for science is a method of discovering the world and not simply a body of facts (Dunbar, 1995). The method requires a theoretical framework that generates testable predictions (subsidiary hypotheses) and this theoretical framework determines what questions to ask and suggests which avenues of research are likely to bear fruit (Lakatos, 1978).

\section{INTEGRATING PSYCHOLOGY AND PSYCHIATRY INTO BIOLOGY}

There seems little doubt that a scientific psychiatry can be developed only by integrating the discipline firmly into the biological sciences, and given that Darwinian theory is at the core of modern biology this seems the ideal overall framework within which a new and reformed scientific psychiatry can be formulated.

If one accepts that humans are evolved biological organisms, that the human brain (as is the case with the rest of the human 
body) is the result of a long process of selection, and that the mind is the product of the human brain and represents a complex set of adaptations that have arisen through a long evolutionary process, then human psychology and sociology could (and should) legitimately be considered as part of the domain of biology (Plotkin, 1997). The misconception lingers among many psychiatrists that biological psychiatry simply equals neurochemistry and genetics. However, the molecular level of brain functioning is no more or less biological than the macro-neurobiological level or the level of organismic behaviour (Dennett, 1995). Nevertheless, it does matter a great deal at what level one decides it would be most appropriate to view a given biological phenomenon in terms of whether or not this level helps shed light on the function of the system for the organism as a whole (Dennett, 1995). Therefore, no amount of study of the molecular structure of muscle tissue will be able to answer the question of what muscles are for (e.g. are they energy storage vesicles, body temperature regulators or organs for locomotion?).

Without answering this basic question it is impossible to generate hypotheses about muscular abnormalities that are still poorly understood, or even to decide whether or not an abnormality exists. However, this is exactly what is done when molecular hypotheses are generated about complex disorders of the nervous system without due regard to the function of the neurobiological system under study. This is as true for the monoamine theory of depression as it is for the dopamine theory of schizophrenia. In such situations it seems highly unlikely that focusing on individual neurotransmitters (through finding simple associations) in such a highly complex organ as the human brain would lead to any significant cumulative advance in our understanding of the complexities of depression or schizophrenia (except perhaps through serendipitous findings). One of the important messages of evolutionary theory, therefore, is that hypotheses about dysfunction can be generated only when the function of a system is understood (or at least suspected) (Bolton \& Hill, 1996).

\section{CONTRIBUTIONS OF THE EVOLUTIONARY PARADIGM}

The major contribution that evolutionary science can make to psychiatry and psychology is to help formulate the right questions that research can then address. There are a number of fields in which the evolutionary paradigm has generated novel hypotheses leading to significant advances in understanding and new directions for research. One such area is that of gender psychological differences. For example, it was predicted that there would be a clear gender difference in the circumstances that give rise to jealousy, based on the known consequences for the reproductive fitness of males and females resulting from the infidelity of a long-term sexual partner. Males were expected to be more distressed by the sexual as opposed to emotional infidelity of their partner, because of paternity uncertainty, whereas females were predicted to show the reverse. Ancestral females, of course, were never uncertain about the genetic relatedness of their offspring, but did suffer a deprivation of resources (and reduced reproductive fitness as a result) when their long-term mate turned his attention to a rival female. This prediction has now been upheld in a number of studies across cultures (Buunk et al, 1996).

Other advances have resulted from the application of the concept of modularity of the mind (Fodor, 1983). This view assumes that the human $\mathrm{mind} / \mathrm{brain}$ is composed of a number of domain-specific, highly tuned systems designed by selection to solve specific sets of problems that would have recurrently confronted ancestral humans in their natural environment (Barkow et al, 1992; Cosmides \& Tooby, 1994; Buss, 1999). This contrasts with the view, prevalent in much of the social sciences, of the human mind/brain as a general-purpose learning apparatus. Mental modules are neurobiological systems that facilitate efficient and effective learning within a specific domain and are capable of rapid computation within a particular area of functioning. The best known mental module, of course, is that connected with language (Pinker, 1994), but there are likely to be a number of other such systems charged with functions such as social reasoning, mating strategy and other complex and vital tasks. The concept of domain specificity has significantly advanced our understanding of the nature of a number of mental disorders (e.g. autism and related disorders) and has led to the uncovering of a range of human mental competences (such as a theory of mind module) that had hitherto remained unknown (BaronCohen, 1997).
The application of evolutionary principles can also shed light on highly complex areas of human behaviour where innumerable factors are at play and where an atheoretical approach can simply become overwhelmed by the weight of the data. One such area is that of human violence, including child abuse and homicide. Nonevolutionary enquiry had suggested that parents frequently abused their offspring and that homicide was frequently the result of parental violence. Although such claims were readily accepted by conventional social science they represented highly puzzling findings for Darwinian investigators. How could it be so common for individuals systematically to harm their own reproductive fitness through abusing and murdering their own offspring? However, when Daly \& Wilson (1988) investigated this phenomenon through enquiring about genetic relatedness, they found that a child living in a household with a step-parent was 100 times more at risk of being fatally abused and 40 times more likely to suffer serious physical abuse than one living with both biological parents. They concluded that living in a household with a stepparent was the single most significant risk factor for being abused as a child. Without the evolutionary perspective such a research question may not have been formulated. Since then, a large body of literature has been created that has helped further understanding of the whole area of step-parenthood and step-parental investment that could not have been possible without such insights (Daly \& Wilson, 1999).

In addition, numerous evolutionary hypotheses have been proposed in the areas of depression (Nesse, 2000), anxiety and related disorders (Marks \& Nesse, 1994), eating disorders (Abed, 1998), obsessivecompulsive disorder (Abed \& de Pauw, 2000) and antisocial personality disorder (Mealey, 1997).

Much uncertainty still surrounds the status of cultural and social factors in the scientific study of human behaviour. However, it is becoming increasingly clear that the conventional social science model that assumes infinite malleability of the human mind and views it as a blank slate cannot be sustained. Furthermore, adopting the evolutionary perspective will lead to the recognition that social and cultural factors cannot be considered as separate and independent causative agents acting independently on individual minds (Plotkin, 1997; Sperber, 1996). Unfortunately, 
psychiatrists have not yet begun a serious debate about such matters. But it is unlikely that the developments in evolutionary science can be ignored for much longer.

\section{ACKNOWLEDGEMENTS}

I am grateful to Dr P. McCrea for reading and commenting on an earlier draft of this paper, and to two anonymous referees for their helpful comments.

\section{REFERENCES}

Abed, R. T. (1998) The sexual competition hypothesis for eating disorders. British Journal of Medical Psychology, 7I, 525-547.

— \& de Pauw (2000) An evolutionary hypothesis for obsessive-compulsive disorder: a psychological immune system? Behavioural Neurology, in press.

Barkow, J. H., Cosmides, L. \& Tooby, J. (1992) The Adapted Mind: Evolutionary Psychology and the Generation of Culture. New York: Oxford University Press.

Baron-Cohen, S. (1997) Mindblindness: An Essay on Autism and Theory of Mind. Cambridge, MA: MIT Press.

Bolton, D. \& Hill, J. (1996) Mind, Meaning and Mental Disorder: The Nature of Causal Explanation in Psychology and Psychiatry. Oxford: Oxford University Press.

Buss, D. M. (1999) Evolutionary Psychology: The New Science of the Mind. Boston, MA: Allyn \& Bacon.

RIADH T. ABED, MRCPsych, Rotherham District General Hospital, Moorgate Road, Rotherham S60 2UD; e-mail: abed@globalnet.co.uk

(First received 10 December 1999, final revision 2 February 2000, accepted 8 February 2000)

Buunk, A. P., Angleitner, A., Oubaid,V., et al (1996) Sex differences in jealousy in evolutionary and cultural perspective: tests from the Netherlands, Germany and the United States. Psychological Science, 7, 359-363.

Cosmides, L. \& Tooby, J. (1994) Origins of domain specificity: the evolution of functional organization. In Mapping the Mind: Domain Specificity in Cognition and Culture (eds L. A. Hirschfeld \& S. A. Gelman), pp. 85116. New York: Cambridge University Press.

Daly, M. \& Wilson, M. (1988) Homicide. New York: Aldine De Gruyter.

_ \& _ (1999) Stepparental investment. Evolution and Human Behaviour, 20, 365-366.

Dennett, D. C. (1995) Darwin's Dangerous /dea: Evolution and the Meanings of Life. New York: Simon \& Schuster.

Dunbar, R. (1995) The Trouble with Science. London: Faber \& Faber.

Fodor, J. (1983) The Modularity of Mind. Cambridge, MA: MIT Press.
Lakatos, I. (1978) The Methodology of Scientific Research Programmes, vol. I. Cambridge: Cambridge University Press.

Marks, I. M. \& Nesse, R. M. (1994) Fear and fitness: an evolutionary analysis of anxiety disorders. Ethology and Sociobiology, 15, 247-261.

McGuire, M. \& Troisi, A. (1998) Darwinian Psychiatry. New York: Oxford University Press.

Mealey, L. (1997) The sociobiology of sociopathy: an integrated evolutionary model. In The Maladapted Mind: Classic Readings in Evolutionary Psychopathology (ed. S. Baron-Cohen), pp. 133-188. Hove: Psychology Press.

Nesse, R. M. (2000) Is depression an adaptation? Archives of General Psychiatry, 57, 14-20.

Pinker, S. (1994) The Language Instinct. London Penguin.

Plotkin, H. (1997) Evolution in Mind: An Introduction to Evolutionary Psychology. Harmondsworth: Allen Lane.

Sperber, D. (1996) Explaining Culture: A Naturalistic Approach. Oxford: Blackwell. 